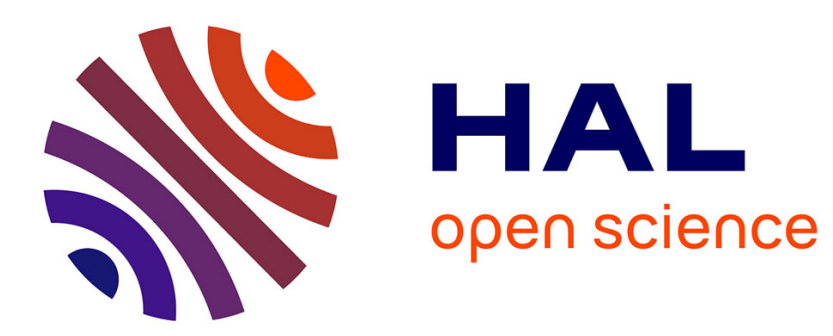

\title{
ELECTRON BEAM WRITING ERASURE SWITCHES
}

Pascal Girard, B. Pistoulet, M. Valenza

\section{To cite this version:}

Pascal Girard, B. Pistoulet, M. Valenza. ELECTRON BEAM WRITING ERASURE SWITCHES. Journal de Physique Colloques, 1988, 49 (C4), pp.C4-805-C4-808. 10.1051/jphyscol:19884169 . jpa00227910

\section{HAL Id: jpa-00227910 https://hal.science/jpa-00227910}

Submitted on 1 Jan 1988

HAL is a multi-disciplinary open access archive for the deposit and dissemination of scientific research documents, whether they are published or not. The documents may come from teaching and research institutions in France or abroad, or from public or private research centers.
L'archive ouverte pluridisciplinaire HAL, est destinée au dépôt et à la diffusion de documents scientifiques de niveau recherche, publiés ou non, émanant des établissements d'enseignement et de recherche français ou étrangers, des laboratoires publics ou privés. 
JOURNAL DE PHYSIOUE

Colloque $C 4$, supplément au $n^{\circ} 9$, Tome 49 , septembre 1988

\title{
ELECTRON BEAM WRITING ERASURE SWITCHES
}

\author{
P. GIRARD, B. PISTOULET and M. VALENZA
}

\section{Laboratoire d'Automatique et de Microelectronique de Montpellier (UA 371). Université des Sciences et Techniques du Languedoc. Place Eugène Batailion, F-34060 Montpellier Cedex, France}

\begin{abstract}
Résumé - Dans cet article, nous montrons pour la première fois, qu'il est possible de faire basculer un transistor Mos à grille flottante de l'état passant à l'état bloqué et réciproquement à partir d'une irradiation par faisceau d'électrons dans un microscope électronique à balayage. Nous déterminons 1 'influence du champ d'extraction sur les rendements de charge positive, et celle de $1^{\prime}$ état électrique initial de la grille flottante sur le potentiel positif atteint. Ces résultats ouvrent la voie au test et à la reconfiguration de circuits intégrés par le seul faisceau délectrons.
\end{abstract}

Abstract - In this paper, it is shown for the first time that an electron beam is able to switch an oxide embedded floating gate MOS transistor from the on to the off state and inversely. These experiments are achieved in a classical Scanning Electron Microscope. We derive the influence of : i) the extraction voltage on the positive charging yield, ii) the initial floating gate voltage on its final positive voltage. These preliminary results open the way to future e-beam testing and reconfiguration method of integrated circuits.

\section{I - INTRODUCTION}

Today the electron beam testing of integrated circuits is coming of age and the equipments now available are consistent with the performances of integrated circuits $/ 1,2 /$. However the interaction of the electrons with sensitive parts of the circuits may lead to new electron beam testing possibilities. For example the activation of switches with the primary electrons is possible without any extra electrical wire/3/. It opens the way to partitioning or reconfiguration of circuits in connection with testing. A first possibility consists in short circuiting a reversely biased junction by the excess electron hole pairs located in the vicinity, this is the EBIC effect. Unfortunately, in order to cross the various oxide sheets above the silicon substrate high energy electrons are required. This may lead to damages on adjacent devices $/ 4 /$ and makes difficult primary energy changes. A second way consists to deposit charges on or above an oxide embedded floating gate Mos transistor. Up to now efficient negative charge deposition has been observed at primary beam energy of $5 / 3 /$ and, more recently of $3 \mathrm{keV} / 5 /$. U1tra violet irradiation is required in order to erase the deposited charge.

In this paper, we report experimental results showing that writing-erasure cycles can be achieved onjy by means of electron beam deposition into the top oxide covering the floating gate of first a negative and secondly a positive charge. The results and the main parameters governing the positive electron beam charging are discussed below.

\section{II -EXPERIMENTS AND DISCUSSIONS}

The experiments have been achieved on $n$ channel depletion mode floating gate transistors embedded in a $700 \mathrm{~nm}$ top oxide. The polysilicon gate dimensions are $25 \times 25 \mathrm{Hm}^{2}$ and the oxide thickness around the gate merges around 2 . $1 \mathrm{~m}$. The devices are irradiated inside an ISI, SS 40 Scanning Electron Microscope. The evolution of the electrical parameters is established using a Hewlett Packard HP 4145 transistor parameter analyser. The charge deposition is obtained in the scanned mode, the surface exposed to the electrons is much larger than the gate of the device.

In a first step the floating gate normally on transistors are shifted in the 
off state by a $3 \mathrm{keV}$ primary beam negative charging /5/. Then positive charging is achieved by irradiating with primary electrons of $1.4 \mathrm{keV}$ and using a 0.28 $\mathrm{kV} / \mathrm{mm}$ extraction field, this switches the device to the on state (fig. 1).

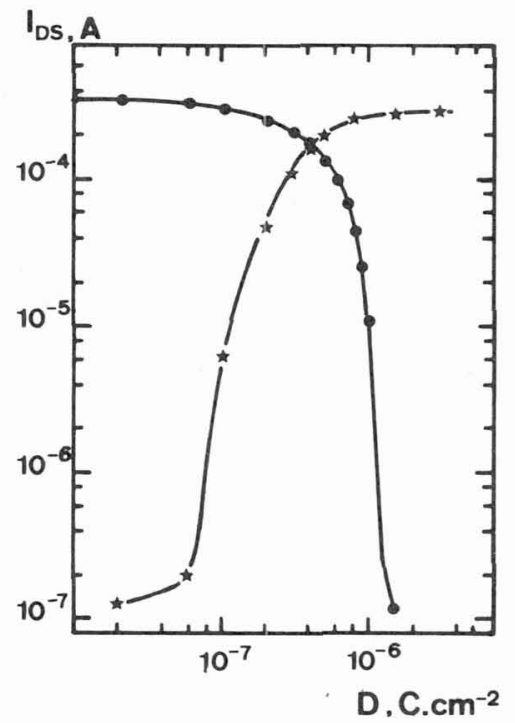

Fig. 1 - Example of the drain source currents of the floating gate Mos transistor, at $5 \mathrm{~V}$ drain source polarisation versus the incident dose. Negative and positive charging correspond respectively to (*) and ( $x$ ).

In both cases, a $3.10^{-6} \mathrm{C} \mathrm{cm}^{-2}$ incident charge is sufficient to obtain a current variation of three orders of magnitude. The parameters driving the negative charging are well established /6/ but, up to now, this is not the case in the positive region. The floating gate voltage variations are deduced /6/ by comparing the electrical characteristics of same size floating gate and normal MOS transistor processed on the same chip. The experimental results are reported on fig. 2 at various extraction fields.

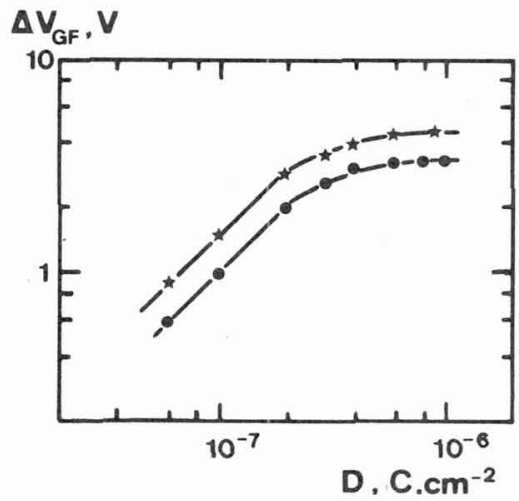

Fig. 2 - Evolution of the positive floating gate voltage variation versus the incident dose. The extraction fields used are respectively $1 \mathrm{kV} / \mathrm{mm}(*)$ and $0.28 \mathrm{kV} / \mathrm{mm}(\bullet)$.

These variations correspond to the difference between the initial -3 V gate voltage and successive steps when positive charging occurs. The deposited charge first increases and then saturates when a final positive voltage is obtained. The limit voltage jncreases with the extraction voltage.

The charging yield $Y$ of the top oxide,i.e. the ratio between deposited and incident charges, depends on the backscattered and on the secondary yields $n$ 
and $\delta\left(E p, \quad X_{j}\right)$ respectively /7/. This last yield depends on the primary beam energy $\mathrm{Ep}$ and also on other parameters $\mathrm{Xj}$ considered below.

The bound voltage is obtained when $Y=\eta+\delta\left(\mathrm{Ep}_{\mathrm{p}}, \mathrm{Xj}\right)-1$ (1) tends towards zero. The yield variation is deduced at various extraction voltages (fig.3) from the evaluation of the charging slope in the linear zone (see fig.2).

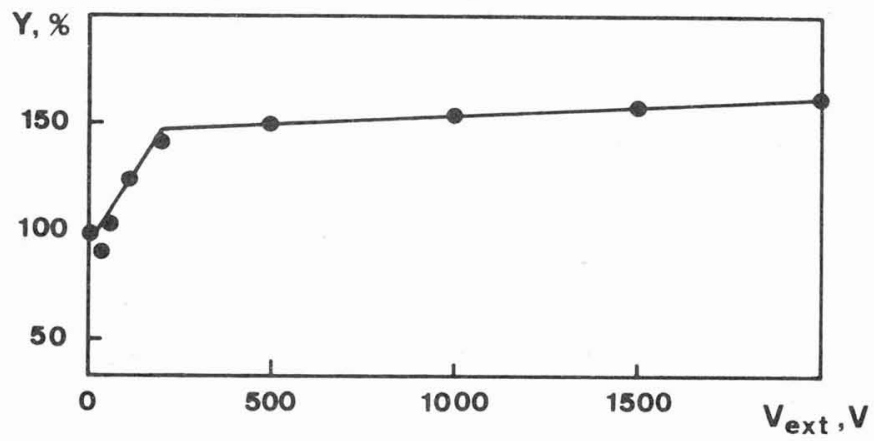

Fig. 3 - Charging yield variations versus extraction voltage.

Since a large planar extracting grid about $1 \mathrm{~cm}$ diameter is placed above the specimen, in the objective lens bore, the homogeneous extraction field strongly affects the electron trajectories. In the first zone the major part of the reemitted electrons is directed out of the insulator surface, while in the second part only the particles. with highest angles of incidence are driven by the field.

The positive saturation voltage reached increases with the extraction voltage (see fig.2), but depends only slowly of the initial voltage of the floating gate within the $-3 \mathrm{~V},+0.75 \mathrm{~V}$ range (fig.4).

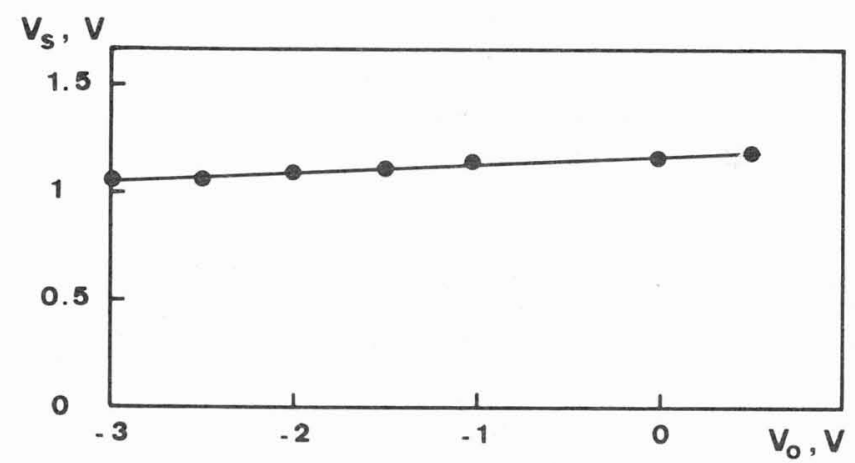

Fig. 4 - Evolution of the saturation voltage at various initial states.

On one hand the limit obtained is largely sufficient to switch on again the transistor. On the other hand it remains higher than the capacitively induced surface voltage, i.e. Vsc $\simeq$ ( Cvacuum / Coxide ) Vextr., which is equal to $0.15 \mathrm{~V}$ on the device.

Let us now come back to the secondary yield which is strongly related to the saturation voltage. It depends on : i) the primary beam energy as currently admitted /7/, ii) the extraction field as established here, iii) the positive surface voltage.

When the voltage is increased, low energy electrons are driven back to it, it gives then a low energy cut off filter. Let us call this function F(Vs), where Vs is the surface potential, it is written

$$
F(V s)=\int_{q_{s}}^{50 e V} N(E) d E / \int_{0}^{50 e V} N(E) d E
$$


with $N(E)=1,5 E \exp \left(2-(8 / 3 E)^{1 / 2}\right)$

is the secondaries energy distribution as established by Kollath /8/.

Consequently if we suppose that oo( Ip) represents the normal secondary yield, i.e. without any surface effect on the electrons trajectories, F(Vs) the filter function, and $G$ (Vextr.) the influence of the extraction field, the effective secondary yield may be written

$$
\delta\left(\operatorname{Ep}, V_{s}, V \operatorname{Vextr} .\right)=\delta_{0}\left(E_{p}\right) \cdot F\left(V_{s}\right) \cdot G\left(V_{e x t r}\right)
$$

Then the final attainable voltage corresponds to :

$$
F\left(V_{s}\right)=(1-n) /\left(\delta_{0}\left(E_{p}\right) \cdot G\left(V_{e x t r}\right)\right)
$$

It is clear that the higher the extraction voltages and the normal yields, the lower the filtering function and the higher the positive surface allowable voltage are. This simple approach gives a qualitative agreement with experiment. In fact, the charging mechanism in presence of an extraction field is a complex phenomenon /9,10,11/ requiring more further developments and studies.

\section{III-CONCLUSION}

We have demonstrated for the first time, that both negative and positive charging of silicon dioxide embedded floating gates Mos transistors are achievable in a Scanning Electron Microscope. The activation of such a switch has been actually demonstrated, and the main parameters for positive charging have been established. It is shown that the extraction field may appreciably change the charging yield and consequently the positive voltage attained by the gate voltage. This parameter is only slowly dependent on the initial gate voltage, so a MOS transistor can be switched from the off to the on state with a current ratio of three orders of magnitude. This work shows that the concept of e-beam testing and reconfiguration using the same tool does not appear unrealistic.

\section{AKNOWLEDGEMENTS}

We acknowledge the EEC for the initial support in the early stages of this work within the ESPRIT 824 project (Wafer Scale Integration).

\section{REFERENCES}

/1/ Menze1 E., Buchanan R., E1ect. Lett., 20, 10 (1985) 408.

/2/ Frosien J., Plies E., Microelectronic Engin.7 (1987) 163, Wo1fgang E., Courtois B. ed., Elsevier Science Pub. (North Hölland), Amsterdam.

/3/ Shaver D.C., J. Vac. Sc. and Techn. 19 (4) (1981) 1010 .

$14 /$ Girard P., Scann. Microsc., 2, 1 (1988) 151 .

/5/ Girard P., Pistoulet B. Valenza M., Lorival R., IFIP Workshop on Wafer Scale Integration, to be published, North Holland.

/6/ Girard P., to be published in Scanning Microscopy.

/7/ Goldstein J.L., Yakowitz H., Practical Scanning Electron Microscopy, Plenum Press, New York (1975).

/8/ Kollath R., Hanbuch der Physik, 21, 241 (1956) Springer Verlag,Germany,

/9/ Brunner M., Menze1 E., J. Vac. Sci. Technology B1 (4) (1983) 1344.

/10/ Nye P., Dinnis A., Scanning, 7 (1985) 117 .

/11/ Reiners W., Herrmann K.D., Kubalek E.,Scann. Microsc.,2, 1 (1988) 161. 